\title{
Role of emergency bilateral internal iliac ligation in postpartum hemorrhage
}

\author{
Sunder Pal Singh ${ }^{1 *}$, Shipra Misra ${ }^{1}$, Naresh Sharma ${ }^{2}$
}

\begin{abstract}
${ }^{1}$ Department of Obstetrics and Gynecology, SHKM Government Medical College, Nuh, Haryana, India
${ }^{2}$ Department of Physiology, SHKM Government Medical College, Nuh, Haryana, India
\end{abstract}

Received: 28 May 2021

Revised: 05 July 2021

Accepted: 06 July 2021

\author{
*Correspondence: \\ Dr. Sunder Pal Singh, \\ E-mail: sunderdahiya@yahoo.co.in
}

Copyright: ( $)$ the author(s), publisher and licensee Medip Academy. This is an open-access article distributed under the terms of the Creative Commons Attribution Non-Commercial License, which permits unrestricted non-commercial use, distribution, and reproduction in any medium, provided the original work is properly cited.

\begin{abstract}
Background: The aim of the study was to determine the effectiveness of emergency bilateral internal iliac ligation in intractable postpartum hemorrhage.

Methods: A retrospective study was done on 33 women who have undergone emergency bilateral internal iliac ligation in obstetrics haemorrhage.

Results: In all of 33 women under this study bilateral internal iliac ligation was performed in emergency. (11) of the cases were of atonic PPH, placenta previa (8), uterine rapture (7), extension of C-section scar (3), vaginal and cervical laceration (3) and uterine perforation (1). hysterectomy was not performed in any of the cases. internal iliac artery was injured in one case during the procedure and was managed successfully but two patients died during and after the BIIL. Conclusions: BIIL is an effective, less time consuming and life-saving procedure in intractable obstetrics hemorrhage if early decision is taken and performed by practiced surgeons.
\end{abstract}

Keywords: Bilateral, Internal iliac artery ligation, Emergency, Interactable postpartum haemorrhage

\section{INTRODUCTION}

Maternal mortality is still a big concern worldwide. $99 \%$ of the maternal mortality takes place in developing world. ${ }^{1}$ Postpartum hemorrhage has been one of the most common causes of maternal mortality and morbidity globally and still causes a big challenge to the obstetricians, even though there has been big advancement of medical science. $^{2}$ PPH occurs in $5 \%$ of total deliveries and contributes to $28 \%$ of the total maternal deaths in developing countries and $8 \%$ of that in developed world. ${ }^{3}$

$80 \%$ of PPH are caused by uterine atony while $20 \%$ of that is caused by obstetric trauma (vaginal and cervical laceration, rapture uterus etc.), retained adherent placenta, uterine inversion and coagulating disorder. ${ }^{4}$ The failure of uterotonic and uterine messagelto control PPH requires immediate surgical intervention to save the life of the patients. The choice of surgical procedure depends upon the patient desire of child birth, parity, extent of hemorrhage and expertise of the surgeon.

Severe postpartum hemorrhage has been generally managed by obstetrics hysterectomy, when medical methods and localized conventional surgical methods fail. However, with improvements of surgical techniques and advancement of medical technology, uterine saving procedures like bilateral internal iliac artery ligation, uterine artery and utero-ovarian artery ligation, uterine compression suture (B-lynch suture, cervico-isthemic suture). Balloon tamponade, intra-aortic balloon catheter placement, aortic compression, uterine tourniquet and intra-operative selective arterial embolization. But bilateral internal iliac artery ligation is preferred method which have high success rate if done by practice hand. BIIL was pioneered by Sir Howard Kelly in 1894, during 
the treatment of intra-operative bleeding in cervical cancer patient. ${ }^{5}$ Earlier this procedure was associated with high rate of complications and low rate to secure hemostasis like nerve injury, in-advent ligature of common iliac artery, injury to ureter and internal iliac vein were the reported complications

Mengert and Buschell later popularized this procedure. Buschell et al advocated that internal iliac artery ligation reduces the blood flow to the pelvis by $49 \%$ and pulse pressure is reduced by $85 \%$ resulting venous pressure in the arterial circuit, thus promoting thrombosis. ${ }^{6}$

Studies show that bilateral ligation of internal iliac artery preserved the fertility as the collateral circulation maintains the re-functioning of the Internal iliac artery and the ovarian artery also provides the blood supply to the uterus. The anastomosis system starts functioning immediately after ligation and virtually abolishes the arterial pulse pressure. This reduces mean blood pressure and blood flow in the collateral system and thus abolishes the trip-hammer effect of arterial pulsations. As a result, ligation changes the distal portion of the artery so that the net pressure remains equal to that in a vein and arterial pulsation is not able to dislodge the clots remained in situ.

BIIL has been proven to be the most effective, less time consuming and simple procedure if carried out by the practiced hands to control the life-threatening postpartum hemorrhage.

\section{Aim and Objective}

The aim and objective of the study was to establish the effectiveness of emergency BIIL in intractable obstetrics hemorrhage.

\section{METHODS}

The retrospective study had been conducted in S.H.K.M Govt. Medical College, Nalhar, Nuh, Haryana in the year of 2017 after approval of ethical committee. Data used in this study was collected from June 2013 to January 2017.

\section{Sample size}

33 patients under reproductive age (15-45) were considered for this study when the conventional method of managing the obstetrics hemorrhage was failed then BIIL was performed.

For the patients who were undergoing C-section under pfannenstiel incision developed the complications of postpartum hemorrhage. The pfannenstiel incision was used to perform BIIL. An infra-umblical midline vertical incision was made for patients who developed obstetrics hemorrhage under any circumstances other than C-section. Bowels were packed away and uterus was pulled out of abdominal cavity. The bifurcation of the common iliac artery was identified via sacral promontory. The peritoneum was incised longitudinally directly over the iliac bifurcation and extended proximally and distally for a few $\mathrm{cm}$. Ureter was retracted laterally. The medial peritoneal flap and medial pelvic contents were retracted medially and lateral flap retracted laterally then blunt dissection was performed around the internal iliac artery opening the areola tissue. Once the bifurcation was exposed, the hypogastric artery was confirmed as the branch coming of at the right angle and coursing medially and inferiorly. The external iliac artery was visually confirmed as passing laterally and superiorly over the psoas muscles to form the common femoral artery beneath the inguinal ligament. Fascia around the internal iliac artery was dissected completely from the surrounding structures and the artery free from internal iliac vein. Right-angled hemostatic forceps were used to separate the plane between artery and vein and gently passed from the lateral to medial side beneath the internal iliac artery about $3 \mathrm{~cm}$ distal to its origin. Ligated the vessel with silk no1 using 3 notes. Palpated the femoral artery and dorsalis pedis for pulsation. Improvements of vital sign, local and vaginal bleeding was observed after the internal iliac artery ligation was performed. Posterior peritoneum was closed by intermittent suture if we used continuous suture, there were chances of kinking of ureter. Abdominal drain was kept and the abdomen was closed in layers.

Microsoft excel was used as statistical tool to calculate percentage of the cases.

\section{Investigation}

$\mathrm{Hb} \%$, BT, CT, blood group, urine albumin, sugar and microscopy were investigated.

\section{RESULTS}

All of the below cases under study were emergency cases where conventional method to control postpartum hemorrhage had failed. Hysterectomy was not carried out in any of the above cases.

Table 1 shows that $33 \%$ (11) of the total cases under study were of atonic PPH. In all cases of atonic PPH, first uterine massage and uterotonic were tried, when this method failed then decision of bilateral internal iliac ligation was taken and simultaneously tight vaginal packing was done. Hemostasis was successfully achieved in all cases, except two where the patients died during or after the procedure.

As per the above table $26 \%$ (8) of total cases were of placenta previa. 7 of these cases were of central placenta previa and 1 case was of placenta percreta. On failure to achieve hemostasis by local suture on placental bed in lower uterine segment, bilateral internal iliac ligation was performed.

1 case of placenta percreta diagnosed during LSCS, a rent of about 3-4 cm was observed in fundal region after the delivery of baby while extracting the placenta. The rent 
was closed by interlocking suture after which the patient developed PPH and managed by BIIL.

$22 \%$ (7) of the PPH cases were caused by uterine rapture. $60 \%$ of which had previous C-section. All of these patients were in critical condition referred by primary or secondary health centers from the periphery. Uterine rapture associated with extension of rapture scar to broad ligament caused hematoma, bleeding and laceration of uterine arteries. These cases were managed by BIIL followed by uterine repair and evacuation of hematoma.

3 cases $(9 \%)$ in above table were caused by extension of $\mathrm{C}$-section in broad ligament associated hematoma and laceration of uterine artery where LSCS were done by the junior consultant. These cases were managed by BIIL followed by local suture and evacuation of hematoma.

2 cases $(7 \%)$ of the total cases were caused by cervical tear where the cervical tear got extended upto the broad ligament. When the bleeding could not be managed by local suturing, BIIL was performed followed by local cervical suturing to achieve hemostasis.

1 case $(3 \%)$ of posterior fornics tear during labour was also managed by BIIL followed by vaginal packing. Tissues at this site were very friable and oozing continuously.

1 case $(3 \%)$ of post evacuation lateral uterine wall perforation was also managed by BIIL followed by local suturing when primary local suture failed to control hemorrhage due to friability of the issues.

Table 1: Indications.

\begin{tabular}{|l|l|}
\hline Indications & $\begin{array}{l}\text { No. of cases } \\
(\mathbf{N}=33)\end{array}$ \\
\hline Atonic PPH & 11 \\
\hline Placenta previa & 8 \\
\hline Uterine rapture & 7 \\
\hline $\begin{array}{l}\text { Extension of C-section incision with } \\
\text { broad ligament hematoma }\end{array}$ & 3 \\
\hline Vaginal and cervical laceration & 3 \\
\hline Post abortal uterine perforation & 1 \\
\hline
\end{tabular}

As per the Table, 2 patients developed left lower extremity edema on the third post-operative day that disappeared after one and a half month by physiotherapy. 1 case of laceration of right internal iliac artery was observed during the ligation of internal iliac artery which was managed by compression of common iliac artery by thumb gauze followed by upper and lower end of the internal iliac artery held by hemostatic clamp then ligated both using silk no. 1. The root cause of this complication was found to be that the patient was obese and assistant was not trained in this procedure. 1 case of vasico-vaginal fistula was reported which was followed by repair of raptured uterus with BIIL. 3 patients had rupture uterus and were observed for decreased bladder capacity post operatively.
Two deaths were reported during and after the procedure, first patient $\mathrm{P}_{8} \mathrm{~L}_{4} \mathrm{~A}_{4}$ came with atonic postpartum hemorrhage with shock after home delivery. After resuscitation, all measures taken to control the PPH failed. Then decision to go for BIIL was taken and the patient died during the procedure due to sudden cardiac arrest.

Another case of maternal death was reported post operatively on $2^{\text {nd }}$ day of BIIL. Though the patient had $\mathrm{P}_{9} \mathrm{~L}_{7} \mathrm{~A}_{2}$ with severe anemia, congested cardiac failure, cardio myopathy with atonic PPH however she died postoperative due to pulmonary edema and congested cardiac failure.

Table 2: Complications.

\begin{tabular}{|l|l|}
\hline Complications & No. of cases \\
\hline Avulsion of internal illiac artery & 1 \\
\hline Fistula formation & 1 \\
\hline Decreased bladder capacity & 3 \\
\hline Mortality & 2 \\
\hline $\begin{array}{l}\text { Unilateral left lower extremity } \\
\text { edema }\end{array}$ & 2 \\
\hline
\end{tabular}

\section{DISCUSSION}

The present study is comparable to the other studies. The success rate of BIIL in our study $(93.9 \%)$ is little higher than that of Simsek et al study (84\%) and Unal et al study $(87.9 \%){ }^{7,8}$ A better success rate in our study could be because of early decision making to take the patients for BIIL after failure of conventional management.

In our study, mortality rate of $(6 \%)$ was reported during and after the BIIL, which is comparable to the mortality rate reported in Simsek et al study $(7 \%) .{ }^{9}$ The results of present study are comparable with Joshi et al study, Bengal et al study which confirm that atonic PPH is the most common indication of BIIL however life-saving method BIIL is underutilized in the management of PPH due to fear of injury to internal iliac vein, ureter and obturator nerve. ${ }^{9,10}$ Our study reports the injury of internal iliac artery while Joshi et al study reported the injury in internal iliac vein. In both the cases injury was successfully managed. ${ }^{9}$

A good understanding of pelvic anatomy, systematic operative technique and gentle handing can minimize these complications. Many obstetricians do not go for BIIL due to fear of injury to internal iliac vein and this study suggest such surgeon to take the caution while passing the right-angled clamp. It should be passed at $3 \mathrm{~cm}$ distal to the origin of internal iliac artery to avoid the injury in internal iliac vein. The clamp needs to be passed from lateral to medial side and it needs to be passed without resistance. In case any resistance is felt, it would mean that there is incomplete dissection of fascia around the internal iliac artery and suggests withdrawal of the clamp and complete the dissection so that the right-angled clamp can 
be passed below the internal artery smoothly. Another suggestion from this study and authors is that before passing the right-angled clamp below internal iliac artery. The internal iliac artery should be mobilized $3 \mathrm{~cm}$ distal to the origin with the help of index finger and thumb to ensure the completeness of the fascia dissection around internal iliac artery.

Author wants to bring the attention to so far ignored but catastrophic complication due to the injury in the internal iliac artery itself. This injury is quite possible if the knotting is not handled correctly. In order to avoid the injury in internal iliac artery during knotting, the knot should be made gently on $\mathrm{C} 2$ without giving any traction on the artery because in pregnancy internal iliac artery is highly vascular and friable. In case this injury occurs, it can be managed by compression of internal iliac artery at its base using the thumb gauze and then both the injured ends of the artery should be held with hemostatic clamps and ligated separately. Quick decision making plays the important role in saving the life of the patient. If the conventional methods of preventing the PPH are not working, a timely decision to go for BIIL becomes the life savior.

Author feels since obstetricians are better exposed to hysterectomy procedures, conventionally they manage $\mathrm{PPH}$ through hysterectomy. However, hysterectomy is more time consuming, leads to more blood loss and chances of intra-operative and post-operative mortality and morbidity are higher. Author feels that all obstetricians should be trained in performing BIIL as it is less time consuming, leads to less blood loss and can help in preserving the uterus and fertility. BIIL is highly recommended for vaginal laceration, hematoma, deep cervical and fornic tear, where locating the bleeding vessel and suturing are very difficult and hysterectomy is not useful in managing hemorrhage.

\section{Limitations}

This study shows the efficacy and effectiveness of BIIL however it also had few limitations as it had been conducted on a small group of patients and covers mainly the patients in emergency condition when most of the patients were hemodynamically unstable and were not thoroughly investigated.

\section{CONCLUSION}

BIIL is a simple, less time consuming and life-saving procedure but required practiced hands and useful to control the PPH from any cause. Hysterectomy is not required in managing $\mathrm{PPH}$, infact BIIL can facilitate uterine repair. Obstetricians should be trained on this life saving procedure so that this can be used more frequently to save the mother.

\section{ACKNOWLEDGMENTS}

I would like to acknowledge and appreciate Rita Malik who has helped me put this study together.

\section{Funding: No funding sources}

Conflict of interest: None declared

Ethical approval: The study was approved by the Institutional Ethics Committee

\section{REFERENCES}

1. WHO. Maternal Mortality, 2019. Available at: https://www.who.int/newsroom/factsheets/detail/mat ernal-mortality. Accessed on 20 May 2021.

2. WHO. WHO recommendations for the prevention and treatment of postpartum haemorrhage. Geneva: WHO; 2018.

3. Chamberlain GVP. The clinical aspects of massive haemorrhage. Maternal Mortality--The Woy Forward. 1st ed. London: RCO; 1992: 54-62.

4. Koh E, Devendra K, Tan LK. B-Lynch suture for the treatment of uterine atony. Singapore Med J. 2009;50(7):693-7.

5. Kelly H. Ligation of both internal iliac arteries for hemorrhage in hysterectomy for carcinoma uteri. Bull John Hopkins Hosp. 1894;5:53.

6. Burchell RC. Physiology of internal iliac artery ligation. J Obstet Gynaecol $\mathrm{Br}$ Commonw. 1968;75:642-51.

7. Simsek Y, Ercan Y, Celik E, Turkcuoglu I, Karaer A, Turhan U, et al. Efficacy of internal iliac artery ligation on the management of postpartum hemorrhage and its impact on the ovarian reserve. $\mathbf{J}$ Turk Soc Obstet Gynecol. 2012;9:153-8.

8. Unal O, Kars B, Buyukbayrak EE, Karsidag AY, Turan C. The effectiveness of bilateral hypogastric artery ligation for obstetric hemorrhage in three different underlying conditions and its impact on future fertility. J Matern Fetal Neonatal Med. 2011;24(10):1273-6.

9. Joshi VM, Otiv SR, Majumder R, Nikam YA, Shrivastava M. Internal iliac artery ligation for arresting postpartum haemorrhage. BJOG. 2007;114:356-61.

10. Bangal V, Kwatra A, Raghav S. Role of Internal Illiac Artery ligation in control of Pelvic Hemorrage. Pravara Med Rev. 2009;1(2):23-5.

Cite this article as: Singh SP, Misra S, Sharma N. Role of emergency bilateral internal iliac ligation in postpartum haemorrhage. Int J Reprod Contracept Obstet Gynecol 2021;10:3086-9. 